\title{
Genetic and molecular identification of three human TPP1 functions in telomerase action: recruitment, activation, and homeostasis set point regulation
}

\author{
Alec N. Sexton, ${ }^{1}$ Samuel G. Regalado, ${ }^{1}$ Christine S. Lai, ${ }^{2}$ Gregory J. Cost, ${ }^{3}$ Colleen M. O'Neil, ${ }^{3}$ \\ Fyodor D. Urnov, ${ }^{3}$ Philip D. Gregory, ${ }^{3}$ Rudolf Jaenisch, ${ }^{2}$ Kathleen Collins, ${ }^{1}$ and Dirk Hockemeyer ${ }^{1}$ \\ ${ }^{1}$ Department of Molecular and Cell Biology, University of California at Berkeley, Berkeley, California 94720, USA; ${ }^{2}$ The \\ Whitehead Institute for Biomedical Research, Cambridge, Massachusetts 02142, USA; ${ }^{3}$ Sangamo BioSciences, Inc., Richmond, \\ California 94804, USA
}

Telomere length homeostasis is essential for the long-term survival of stem cells, and its set point determines the proliferative capacity of differentiated cell lineages by restricting the reservoir of telomeric repeats. Knockdown and overexpression studies in human tumor cells showed that the shelterin subunit TPP1 recruits telomerase to telomeres through a region termed the TEL patch. However, these studies do not resolve whether the TPP1 TEL patch is the only mechanism for telomerase recruitment and whether telomerase regulation studied in tumor cells is representative of nontransformed cells such as stem cells. Using genome engineering of human embryonic stem cells, which have physiological telomere length homeostasis, we establish that the TPP1 TEL patch is genetically essential for telomere elongation and thus long-term cell viability. Furthermore, genetic bypass, protein fusion, and intragenic complementation assays define two distinct additional mechanisms of TPP1 involvement in telomerase action at telomeres. We demonstrate that TPP1 provides an essential step of telomerase activation as well as feedback regulation of telomerase by telomere length, which is necessary to determine the appropriate telomere length set point in human embryonic stem cells. These studies reveal and resolve multiple TPP1 roles in telomere elongation and stem cell telomere length homeostasis.

[Keywords: embryonic stem cells; human genome engineering; shelterin; telomerase; telomere maintenance]

Supplemental material is available for this article.

Received June 5, 2014; revised version accepted July 28, 2014.

Telomere length in human somatic cells sets a boundary for their proliferative capacity, allowing the growth and tissue renewal necessary for the human life span while restricting excessive malignant growth deleterious to tissue function (Shay and Wright 2005). During human embryogenesis, telomere lengths in somatic cell lineages are established such that they can support a complex developmental program while remaining short enough so that telomere attrition can contribute to tumor suppression in the adult (Aubert 2014). Elucidating the mechanisms that determine stable telomere length homeostasis and the telomere length set point in embryonic stem cells is therefore fundamental to our understanding of normal cellular renewal and its deregulation in cancers. Telomere

Corresponding authors: hockemeyer@berkeley.edu, kcollins@berkeley.edu Article published online ahead of print. Article and publication date are online at http://www.genesdev.org/cgi/doi/10.1101/gad.246819.114. maintenance critically depends on the shelterin protein complexes that protect genome integrity by forming specialized telomeric chromatin (Palm and de Lange 2008; Cesare and Karlseder 2012). Shelterin protein complexes contain TRF1 and TRF2 bound to double-stranded telomeric repeats, POT1 bound to single-stranded telomeric repeats, and TIN2 and TPP1 bridging these direct DNA-binding proteins. Compromised shelterin function can lead to telomere deprotection, activation of DNA damage responses, and inappropriate genomic rearrangements by DNA repair pathways that ultimately lead to cell cycle arrest or cell death (Palm and de Lange 2008; Cesare

(C) 2014 Sexton et al. This article is distributed exclusively by Cold Spring Harbor Laboratory Press for the first six months after the full-issue publication date (see http://genesdev.cshlp.org/site/misc/terms.xhtml). After six months, it is available under a Creative Commons License (Attribution-NonCommercial 4.0 International), as described at http:// creativecommons.org/licenses/by-nc/4.0/. 
and Karlseder 2012). Importantly, in addition to its endprotective functions, the shelterin complex both negatively regulates telomere elongation by sequestering the chromosome 3' end from telomerase and stimulates telomere elongation by recruiting telomerase for new telomeric repeat synthesis (Nandakumar and Cech 2013).

The interdependence of TPP1, POT1, and other shelterin components for telomere binding presents a challenge for dissecting individual protein contributions to telomere length homeostasis. Depletion and overexpression experiments establish TPP1 and POT1 as negative regulators of telomere length (Loayza and de Lange 2003; Houghtaling et al. 2004; Liu et al. 2004; Ye et al. 2004; Hockemeyer et al. 2007; Churikov and Price 2008; Baumann and Price 2010). Recent studies using protein expression knockdown suggest that TPP1 also promotes telomerase activity at telomeres (Lue et al. 2013; Nakashima et al. 2013). The TPP1 oligonucleotide/oligosaccharide-binding fold (OB) and specifically an OB surface termed the TEL patch mediate the interaction of TPP1 and telomerase assayed by coimmunopurification of overexpressed proteins from cell extract, cellular colocalization of overexpressed proteins, and extent of telomere elongation in human tumor cell lines (Wang et al. 2007; Xin et al. 2007; Abreu et al. 2010; Tejera et al. 2010; Nandakumar et al. 2012; Sexton et al. 2012; Zhong et al. 2012). Importantly, shelterin integrity is not detectably compromised by overexpressed TPP1 that either lacks the $\mathrm{OB}(\Delta \mathrm{OB})$ or is mutated in the TEL patch (Xin et al. 2007; Nandakumar et al. 2012), establishing that these mutant TPP1 proteins are disrupted specifically for telomerase interaction and not for TPP1 telomere-protective functions. Previous studies that tested mutant TPP1 function in human tumor cell lines relied on substantial overexpression of TPP1 mutants in the presence of residual wild-type protein, and expression of the wild-type TPP1 increased with time in culture (Nakashima et al. 2013). Thus, previous studies have not been able to determine whether telomerase interaction with the TPP1 TEL patch is a genetically exclusive mechanism for human telomerase recruitment to telomeres or whether telomerase also can act at telomeres independently of the TPP1 TEL patch. Indeed, previous studies suggest secondary recruitment mechanisms for human telomerase dependent on telomere length, telomerase levels, or whether telomerase is concentrated in Cajal bodies (Zhao et al. 2011; Stern et al. 2012).

Although overexpressed TPP1 OB alone is sufficient to localize telomerase to an ectopic site (Zhong et al. 2012), shelterin protein stoichiometry suggests that the physiological TPP1-telomerase interaction would occur in the context of the TPP1-POT1 heterodimer (Takai et al. 2010). Numerous telomerase regulatory activities have been ascribed to POT1 based on in vitro enzyme activity assays, including competition for telomerase binding to singlestranded DNA or enhancement of telomerase binding to the same substrates by suppression of guanosine quadruplex structures (Kelleher et al. 2005; Lei et al. 2005; Zaug et al. 2005). TPP1-POT1 interaction requires the POT1-binding domain (PBD) within TPP1 and the C terminus of POT1. Purified recombinant TPP1-POT1 can stimulate the repeat addition processivity (RAP) of human telomerase approximately threefold, dependent on the TEL patch and specific residues in the TERT N-terminal (TEN) domain (Wang et al. 2007; Zaug et al. 2010; Nandakumar et al. 2012). Increased RAP is dependent on the addition of recombinant TPP1-POT1 directly to telomerase activity assays and the optimal positioning of a POT1-TPP1binding site at the primer $5^{\prime}$ end (Wang et al. 2007). Thus, it remains unresolved whether a stable ternary complex of telomerase, TPP1, and POT1 would compete, facilitate, and/or change the RAP of telomere elongation.

The interpretation of previous studies that have used RNAi to deplete shelterin proteins in human tumor cell lines is limited by not only residual wild-type protein but also tumor-specific alterations in chromosome number and the aberrant process of telomerase activation in tumor cells (Kim et al. 1994; Bryan et al. 1998; Nakashima et al. 2013), which could change the physiological requirements for telomerase access to telomeres. Studies using mouse models are complicated by their atypically long telomeric repeat tracts (Kipling and Cooke 1990). Here, we introduce the use of human embryonic stem cells (hESCs) to address open questions about physiological telomere length homeostasis with a rigorous genetic approach. We show by targeted gene replacement that the TEL patch of TPP1 is essential for new telomeric repeat synthesis and that TEL patch-deficient cells phenocopy the consequences of homozygous disruption of TERT in hESCs. Unexpectedly, the TEL patch remained essential even with the bypass of its role in telomerase recruitment, suggesting that the TEL patch has a second essential role as a telomerase activator. Moreover, using intragenic complementation, we show that neither of these essential roles requires a contiguous telomerase-TPP1-POT1 ternary complex with 1:1:1 subunit stoichiometry. Additionally, we identify a TPP1 mutation distant from the TEL patch that allows stable telomere maintenance but at a shorter telomere length set point of homeostasis, demonstrating that TPP1 provides feedback regulation of telomerase action responsive to telomere length. These genetically defined requirements for telomerase action in human cells reveal an unexpected multiplicity of roles for TPP1.

\section{Results}

The TPP1 TEL patch is essential for telomere elongation in hESCs

To conduct a genetic analysis of human TPP1 requirements for telomerase action, we used genome-editing technologies that we previously established for the efficient genetic manipulation of human pluripotent stem cells (Hockemeyer and Jaenisch 2010; Hockemeyer et al. 2009, 2011). Specifically, we used zinc finger nucleases (ZFNs) that target the second exon of TPP1 in combination with a donor plasmid to facilitate homology-directed repair of the endogenous TPP1 locus in WIBR\#3 hESCs. We used this approach to edit the TPP1 locus to express a TPP1 variant in which the acidic loop of the TEL patch (amino acids 166-172) was replaced with a GSSG linker 
(TPP1 $\Delta$ L) (Fig. 1A; Supplemental Fig. 1). Importantly, we chose to engineer hESCs to carry this entire acidic loop deletion because it abrogated TPP1-telomerase association assayed by overexpression in HEK293T cells beyond the incomplete inhibition imposed by any previously reported single amino acid substitution (Fig. 1B; Nandakumar et al. 2012; Sexton et al. 2012; Zhong et al. 2012). In addition to mutating the TEL patch acidic loop, our TPP1editing strategy introduced a GFP tag at the $\mathrm{C}$ terminus of the TPP1 $\Delta \mathrm{L}$ variant expressed from the endogenous locus. Targeting was highly efficient and resulted in heterozygous and homozygous targeted clones in a single targeting step. The resulting TPP1 $\triangle \mathrm{L}$-GFP protein localized to telomeres as determined by chromatin immunoprecipitation (ChIP) analysis and immunofluorescence microscopy (IF) (Fig. 1C,D; data not shown). Consistent with previous experiments showing that the TPP1 OB is dispensable for the end-protective shelterin functions of TPP1 (Xin et al. 2007), the engineered TPP1 $\Delta$ L-GFP cells did not present with telomere dysfunction-induced foci (TIFs), proliferated initially with the same kinetics as the wild-type cells, and could be passaged synchronously with the parental cell line.

The hESC genome-editing approach eliminated endogenous TPP1 expression, allowing long-term telomere length analysis without the potential for reversion to wild-type TPP1 expression noted in previous studies (Nakashima et al. 2013). We analyzed telomere length dynamics over multiple months of continuous culture of wild-type, heterozygous $(\Delta \mathrm{L} /+)$, and homozygous $(\Delta \mathrm{L} / \Delta \mathrm{L})$ hESCs. Telomere length remained stable in wild-type and heterozygous $\Delta \mathrm{L} /+$ cells $(n=2$ independent cell lines examined) but progressively decreased in homozygous $\Delta \mathrm{L} / \Delta \mathrm{L}$ cells $(n=4$ independent cell lines examined) (Fig. 2A,B). Initially, TPP1 $\Delta \mathrm{L} / \Delta \mathrm{L}$ cells proliferated at a wild-type rate, with doubling times indistinguishable from heterozygous TPP $1 \Delta \mathrm{L} /+$ and parental hESCs. However, an abrupt decrease in proliferation was observed over $\sim 2$ wk when telomeres reached $2.5-3 \mathrm{~kb}$ in average length, and all cells died $\sim 90 \mathrm{~d}$ after targeting. Even at very late time points, $\sim 80 \mathrm{~d}$ after targeting, TPP1 $\Delta \mathrm{L} / \Delta \mathrm{L}$ hESC cultures still contained mostly pluripotent cells monitored at the single-cell level for OCT4 expression by IF (Fig. 2C). However, these OCT4positive cells at late time points had a readily detectable change in nuclear morphology, with lobulated, blebbed nuclei indicative of cells undergoing apoptosis (Fig. 2C,D). This increase in numbers of early apoptotic cells was accompanied by an increase in dead cells detaching from TPP1 $\Delta \mathrm{L} / \Delta \mathrm{L}$ hESC colonies. At $90 \mathrm{~d}$ after targeting, the only TPP $1 \Delta \mathrm{L} / \Delta \mathrm{L}$ cells remaining in the culture were a small number of spontaneously differentiated cells, which are normally observed in hESCs cultures and were not proliferating and thus did not undergo additional telomere

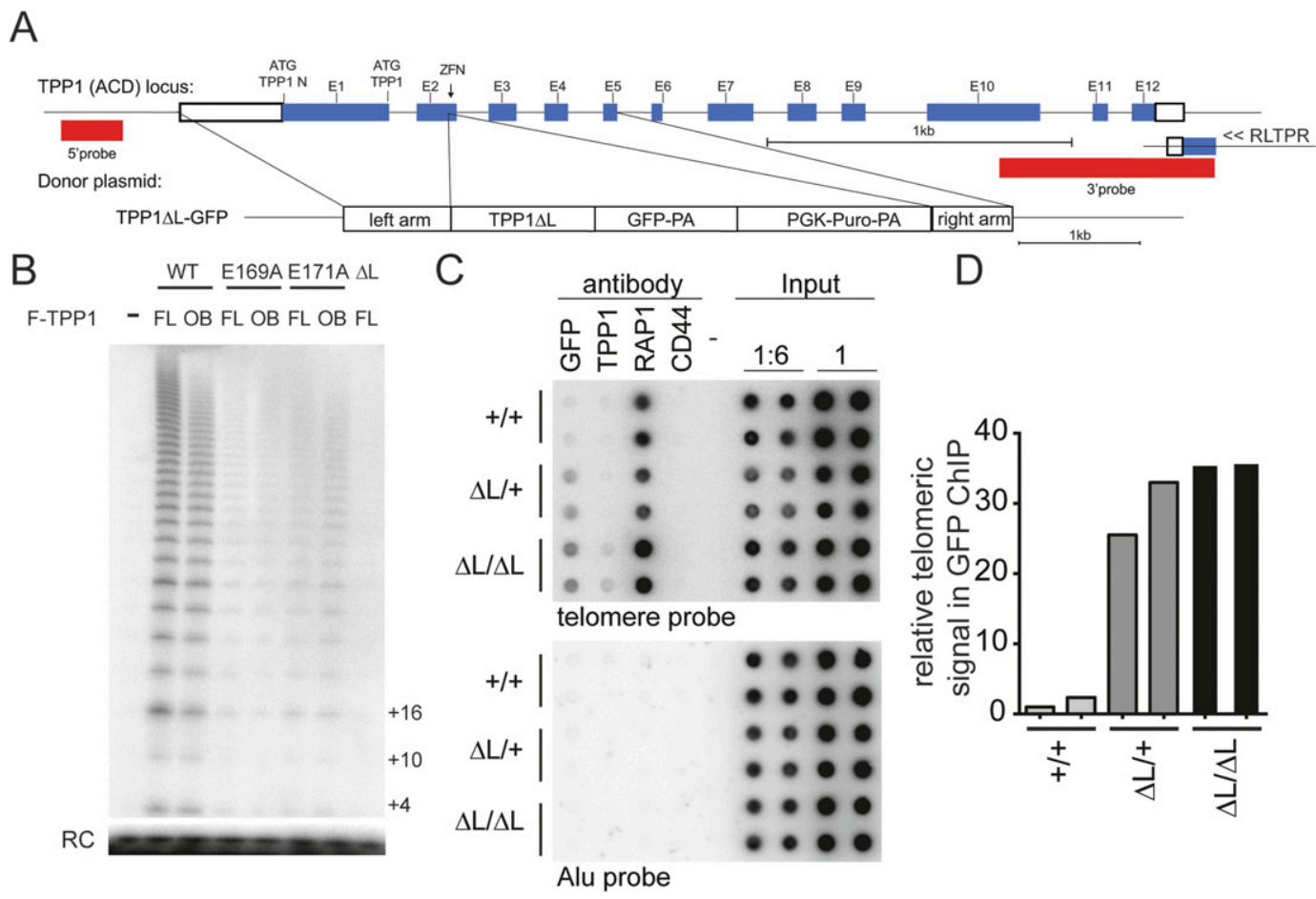

Figure 1. Establishment of TPP1 TEL patch-deficient hESCs. (A) Targeting schematic for ZFN-mediated editing of human TPP1 using homology-directed repair to introduce a C-terminally GFP-tagged TPP1 $\Delta \mathrm{L}$ allele in the endogenous TPP1 locus. ATG indicates the endogenous translation start sites encoding TPP1 or TPP1 $\mathrm{N}$ as indicated. (E) Exon; (PA) polyadenylation signal. $(B)$ Telomerase primer extension activity from HEK293T overexpression and Flag immunoprecipitation of F-TPP1 full-length (FL) or OB overexpressed with zz-TERT and hTR. (RC) Recovery control. (C) ChIP of wild-type $(\mathrm{WT})(+/+)$ or heterozygous $(\Delta \mathrm{L} /+)$ or homozygous $(\Delta \mathrm{L} / \Delta \mathrm{L})$ TPP1 $\Delta \mathrm{L}-\mathrm{GFP}$ cell extracts assayed in duplicate. $(D)$ Quantification of relative levels of telomeric repeat association with GFP normalized to input telomere signal for results in $C$. Alu repeat association is shown as a control for immunoprecipitation specificity. 
A
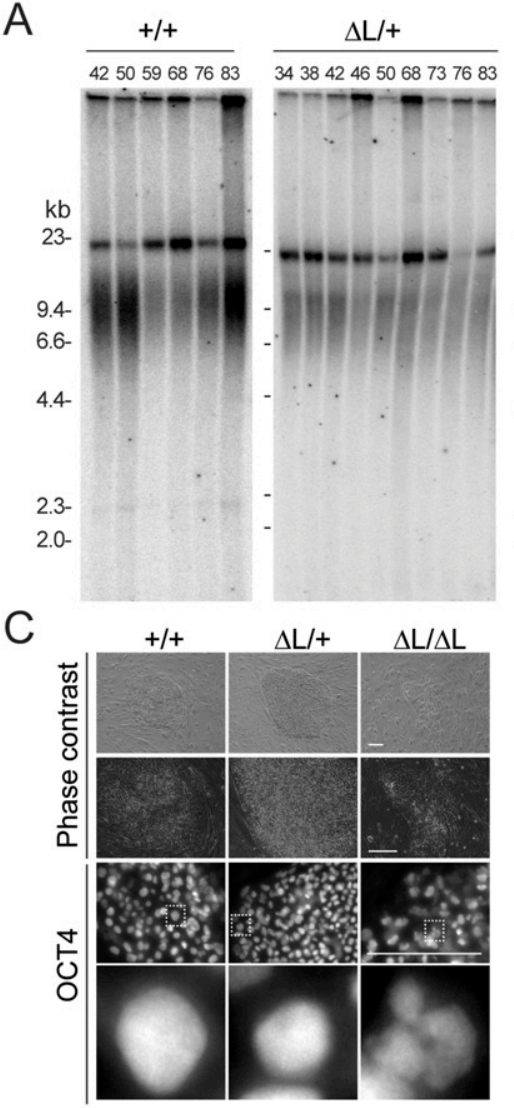

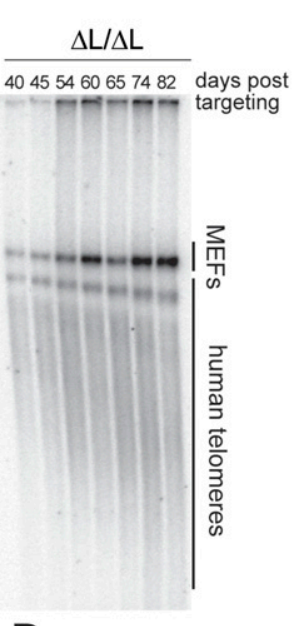

$\mathrm{D}$

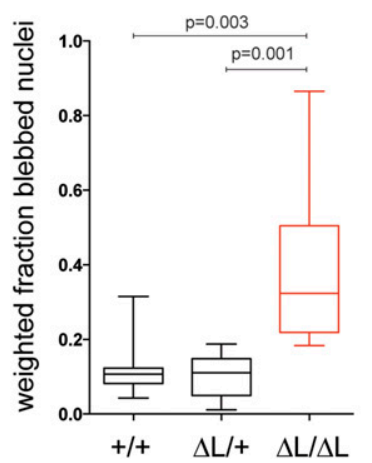

B

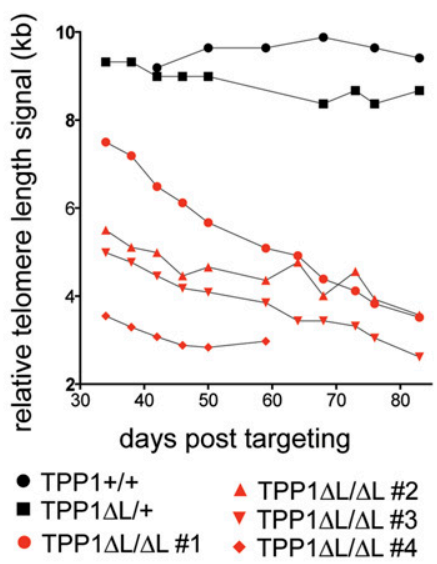

Figure 2. The TPP1 TEL patch is essential for telomere maintenance in hESCs. $(A)$ Telomere restriction fragment length assay of wildtype (WT) or heterozygous or homozygous TPP1 $\Delta$ L-GFP lines over a time course of continuous passaging. $(B)$ Quantification of telomeric repeat hybridization signal lengths in homozygous TPP1 $\Delta$ L-GFP cell lines as compared with wild-type and heterozygous TPP1 $\Delta$ L-GFP lines over continuous passaging. $(C$, top $)$ Phase-contrast images of late time point colony morphology. (Bottom) IF of late time point hESC colonies stained against OCT4, with magnification of the indicated boxed representative nuclei below. Bar, $200 \mu \mathrm{m}$. $(D)$ Box plot of quantification of nuclear blebbing wild-type or heterozygous or homozygous TPP1 $\Delta$ L-GFP at a late time point.

shortening. Control experiments conducted in parallel established that telomeres were maintained in cells that were edited to express the wild-type TPP1-GFP from the endogenous locus (Supplemental Fig. 1). Furthermore, a genetic replacement strategy exploiting an inducibly deleted transgene recapitulated the same loss of telomere maintenance specific to the TPP1 $\Delta \mathrm{L} / \Delta \mathrm{L}$ genotype (Supplemental Fig. 1).

These findings are in contrast to murine ESC cultures that can escape short telomere-induced cell death by activation of a telomerase-independent alternative telomere maintenance pathway (Niida et al. 2000). In the course of analyzing TPP1 $\Delta \mathrm{L} / \Delta \mathrm{L}$ hESCs and additional experiments described below, no telomerase-independent pathway for survival of proliferating hESCs was observed. We conclude that in hESCs, telomerase action through the TPP1 TEL patch is an essential step of telomere maintenance.

\section{TEL patch disruption phenotypes are indistinguishable from TERT knockout}

To test whether TPP1 TEL patch disruption was as severe as complete loss of telomerase function and/or whether it imposed a compounded growth phenotype by disruption of shelterin as well as telomerase function, we compared the TPP $1 \Delta \mathrm{L} / \Delta \mathrm{L}$ hESC phenotypes with those of hESCs lacking active telomerase. We again used ZFNmediated genome editing to generate TERT-deficient (TERT ${ }^{-/}$) WIBR\#3 hESCs by integrating a STOP cassette into the first exon of the TERT gene (Fig. 3A; Supplemental Fig. 2). We then directly compared TERT $^{-1-}$ and TPP $1 \Delta \mathrm{L} / \Delta \mathrm{L}$ cells. While telomerase activity was readily detectable in the parental hESC extract at a level comparable with that of immortalized human cell lines (Supplemental Fig. 2C), homozygous TERT disruption in several independent clonal lines eliminated telomerase activity (Fig. 3B; Supplemental Fig. 2D). Homozygous loss of TERT ( $n=3$ independent cell lines examined) resulted in no detectable change of initial proliferation rates compared with TERT $^{+/-}$hESCs $(n=2$ independent cell lines examined) or the parental line. As expected, TERT ${ }^{-/-}$cell lines exhibited progressive telomere shortening, while $\mathrm{TERT}^{+/-}$cell lines retained telomere length maintenance (Fig. 3C,D). The slight shortening of telomeres in TERT $^{+/-}$ cells compared with parental wild-type cells may derive from clonal variability rather than TERT haploinsuffi- 


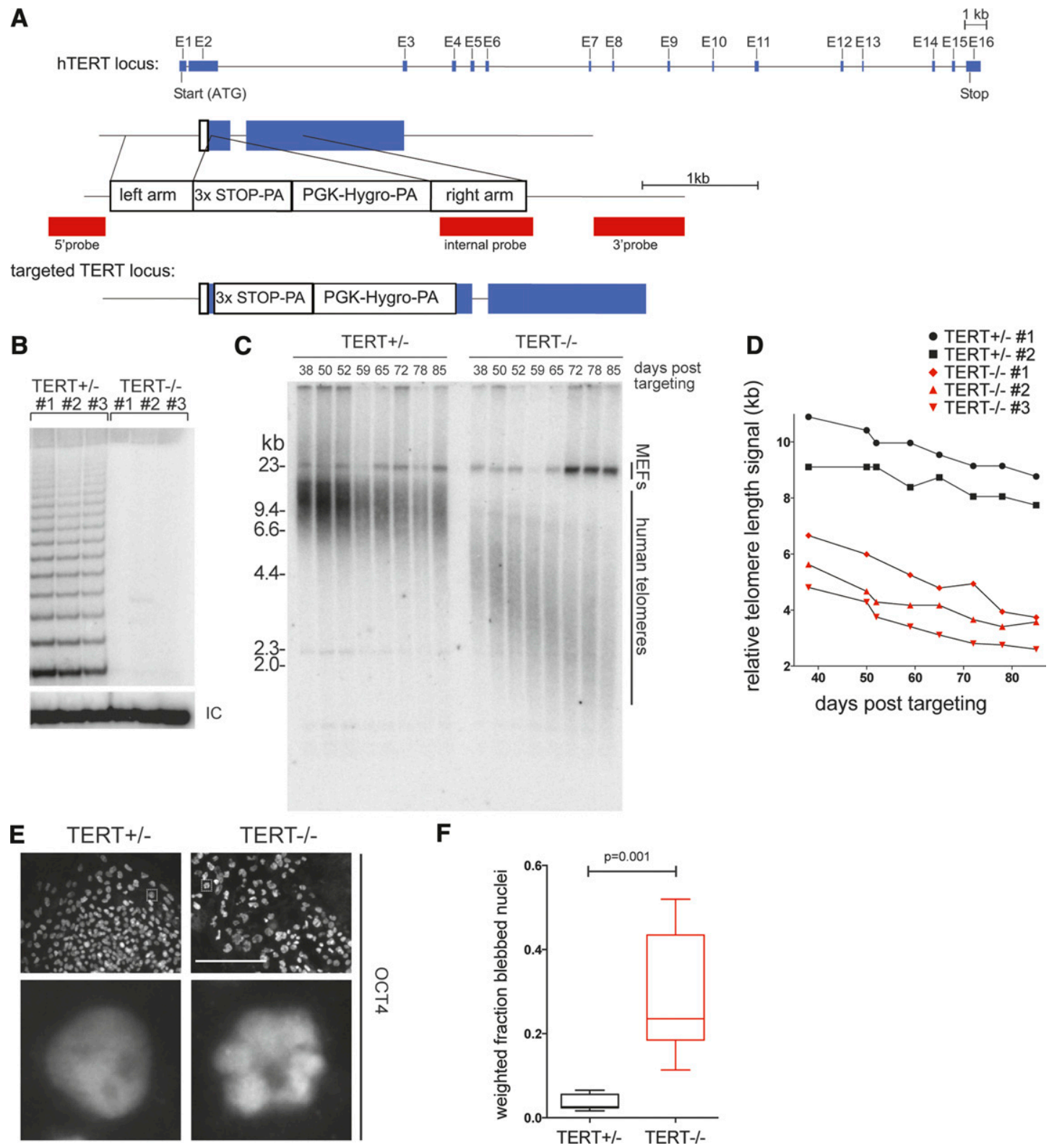

Figure 3. TERT knockout phenocopies TPP1 $\Delta \mathrm{L}$ time course of failures in telomere maintenance and cellular renewal. $(A)$ Targeting schematic for ZFN-mediated integration of a STOP cassette into the endogenous TERT locus. $(B)$ TRAP assay of whole-cell extracts from independent TERT $^{+/-}$and TERT ${ }^{-/-}$cell lines $(n=3$ each) using $333 \mathrm{ng}$ of total protein. (IC) Internal control. (C) Telomere restriction fragment length assay of $\mathrm{TERT}^{+/-}$and $\mathrm{TERT}^{-/-}$cell lines over a time course of continuous passaging. $(D)$ Quantification of telomeric repeat hybridization signal lengths in $\mathrm{TERT}^{+/-}$and $\mathrm{TERT}^{-/-}$cell lines over a time course of continuous passaging, including those from $B$. (E) IF of late time point TERT $^{+/-}$and TERT ${ }^{-1-}$ cell lines stained against OCT4. Bar, $200 \mu \mathrm{m}$. Dashed square in the top panels indicates an individual nucleus for each genotype that is shown magnified in the bottom panel. (F) Box plot of quantification of nuclear blebbing of late time point $\mathrm{TERT}^{+/-}$and $\mathrm{TERT}^{-/-}$cell lines.

ciency in hESCs, as TERT ${ }^{+/-}$cells could be maintained in long-term culture ( $>190 \mathrm{~d})$ with stable telomere lengths (Supplemental Fig. 2E).

All TERT ${ }^{-/-}$cell lines exhibited reduced proliferation starting $\sim 75 \mathrm{~d}$ after the loss of telomerase function. Around $90 \mathrm{~d}$ after telomerase loss, corresponding to telomere lengths of $\sim 2.5-3 \mathrm{~kb}$, proliferating cells were no longer detectable in the TERT ${ }^{-/-}$hESC cultures. The rate of telomere shortening and the number of post-targeting days of continuous passage prior to cell death were indistinguishable from TPP $1 \Delta \mathrm{L} / \Delta \mathrm{L}$ lines. Late passage TERT ${ }^{-/-}$cells also presented the same nuclear blebbing and cell sloughing observed for TPP1 $\Delta \mathrm{L} / \Delta \mathrm{L}$ cells (Fig. $3 \mathrm{E}, \mathrm{F}$ ), thus phenocopying the cell death as well as the proliferative limit of TPP1 $\Delta \mathrm{L} / \Delta \mathrm{L}$ cells. Similar to the TPP1 $\Delta \mathrm{L} / \Delta \mathrm{L}$ hESCs, TERT $^{-/-}$hESCs retained pluripotency until cell death, as indicated by expression of the pluripotency marker OCT4 (Fig. 3E). Also TERT ${ }^{-/-}$hESCs did not yield any prolifer- 
ating survivor cells, with only differentiated cells remaining after $90 \mathrm{~d}$, which again phenocopied the late stage TPP1 $\Delta \mathrm{L} / \Delta \mathrm{L}$ hESC cultures. In genetic epistasis experiments, hESCs double-targeted to have the genotype of $\mathrm{TERT}^{-/-}$and TPP1 $\Delta \mathrm{L} / \Delta \mathrm{L}$ had proliferation intervals to cell death and telomere loss (Supplemental Fig. 2F) that were indistinguishable from hESCs with either single gene replacement, demonstrating that the TPP1 TEL patch and telomerase function in the same genetic pathway. Collectively, these findings demonstrate that the TPP1 $\Delta \mathrm{L}$ substitution of wild-type TPP1 does not exacerbate telomere shortening by imposing any growth-limiting compromise of shelterin but instead selectively and completely eliminates telomerase action at telomeres.

\section{TPP1 $\triangle L$ or TERT overexpression does not bypass TEL patch function}

Many factors contribute directly or indirectly to telomerase action at telomeres in human tumor cells, including telomerase and shelterin component abundance (van Steensel and de Lange 1997; Palm and de Lange 2008; Nandakumar and Cech 2013). Consistent with findings for human tumor cells, hESC telomere length was influenced by the level of shelterin component expression (Supplemental Fig. 3A, B). To investigate whether the telomere maintenance defect in TPP1 $\Delta \mathrm{L} / \Delta \mathrm{L}$ hESCs can be rescued by increased expression levels of TPP1 $\Delta \mathrm{L}$ or TERT, we exploited ZFNmediated targeting for integration of these factors at the AAVS1 locus. In previous experiments, we established the AAVS1 site as a safe harbor locus in hESCs that can be targeted with high efficiency to support robust transgene expression (Hockemeyer et al. 2009, 2011). We used this approach in TPP1 $\Delta \mathrm{L} / \Delta \mathrm{L}$ cells to integrate transgenes directing strong constitutive expression of Flag-tagged TPP1 (TPP1-F), TPP1 $\Delta \mathrm{L}$ (TPP1 $\Delta \mathrm{L}-\mathrm{F})$, or TERT (Fig. 4A; Supplemental Fig. 3). IF confirmed that both TPP1-F and TPP1 $\Delta \mathrm{L}-\mathrm{F}$ localized to telomeres (Fig. $4 \mathrm{~B}$ ), and immunoblot analysis confirmed overexpression of TERT from the AAVS1 locus despite modest, if any, increase in telomerase activity assayed in cell extracts (Supplemental Fig. 3C,D). Analysis of individual clonal cell lines (Fig. 4C) or pooled cell populations (Fig. 4D) revealed that TPP1-F but not TPP1 $\Delta$ L-F or TERT overexpression rescued telomere shortening. With TPP1-F expression, telomeres elongated and were then maintained at lengths comparable with telomeres of the parental hESCs (Fig. 4D). Accordingly, expression of TPP1-F but not TPP1 $\Delta$ L-F or TERT suppressed nuclear blebbing and cell death in the TPP1 $\Delta \mathrm{L} / \Delta \mathrm{L}$ cells (Fig. 4E).

In parallel, we tested the rescue of TPP $1 \Delta \mathrm{L} / \Delta \mathrm{L}$ cells by expression of TPP1 lacking the entire OB (TPP1 $1 \mathrm{OB})$ or TPP1 N, a TPP1 isoform that carries an N-terminal extension due to initiation from an alternative endogenous start site (Fig. 1A). TPP1 $1 \mathrm{OB}$ expression did not forestall telomere shortening or cell death, whereas, like the shorter TPP1-F, TPP1 N expression led to telomere elongation and restored cell viability (Supplemental Fig. 3E,F). These findings underscore the genetically essential role of the TEL patch for telomerase action and telomere maintenance in hESC.

\section{Telomerase action at telomeres requires activation through the TPP1 TEL patch}

Defects in the physical recruitment of telomerase to telomeres can be suppressed by direct fusion of TERT to a telomeric DNA-binding domain or protein (Evans and Lundblad 1999; Armbruster et al. 2004). To test whether the telomere maintenance failure of TPP1 $\Delta \mathrm{L} / \Delta \mathrm{L}$ cells can be rescued by forcing telomerase physical association with telomeres, we targeted the AAVS1 locus for integration of a transgene expressing a TERT fusion with TPP1 $\Delta \mathrm{L}$ (TPP1 $\Delta$ L-F-TERT) (Fig. 5A). We also targeted AAVS1 to express TPP1 $\Delta$ L-F-TERT R132D using TERT with the TEN domain substitution R132D that preserved telomerase catalytic activity but disrupted telomerase recruitment to telomeres (Stern et al. 2012) and strongly diminished telomerase association with TPP1 (Fig. 5B). In parallel, we expressed F-TERT, F-TERT R132D, TPP1-F, and TPP1-FTERT (Fig. 5A; Supplemental Fig. 4). All of the fusion proteins containing TPP1 or TPP1 $\Delta$ L localized to hESC telomeres (Fig. 5C), and all of the fusion proteins containing TERT or TERT R132D reconstituted telomerase with high activity, unlike reconstitution with the TERT G100V substitution (Supplemental Fig. 4A) previously shown to abrogate TPP1 interaction with telomerase and telomerase RAP stimulation in vitro (Zaug et al. 2010; Sexton et al. 2012).

We compared the fusion proteins for their ability to confer telomere length maintenance to both a homozygous $\mathrm{TERT}^{-/-}$cell line and a homozygous TPP1 $\Delta \mathrm{L} / \Delta \mathrm{L}$ cell line. Surprisingly, only a fusion protein containing wild-type TERT (TPP1-F-TERT or TPP1 $\Delta$ L-F-TERT) was able to rescue telomere length maintenance in $\mathrm{TERT}^{-/-}$ cells (Fig. 5D, left panel). In contrast TERT $^{-/-}$cells expressing TPP1 $\Delta$ L-F-TERT R132D had telomere shortening indistinguishable from the untargeted TERT $^{-/-}$ cells or TERT $^{-/-}$cells expressing F-TERT R132D (Fig. $5 \mathrm{D}$, left panel). For the TPP1 $\Delta \mathrm{L} / \Delta \mathrm{L}$ cells, telomere length maintenance was rescued by expression of TPP1-F or the TPP1-F-TERT fusion protein containing intact TPP1 but not by the fusion protein TPP1 $\Delta$ L-F-TERT or TPP1 $\Delta$ L-FTERT R132D (Fig. 5D, middle panel). Taken together, these findings indicate that a fusion protein, TPP1-FTERT, provides TPP1 and TERT function individually, but protein fusion does not bypass the requirement for TEL patch function in telomerase action at telomeres. Thus, the TEL patch of TPP1 plays a telomerase activation role that remains essential even in cells with TEL patch-independent telomerase localization to telomeres by covalent tethering to a telomere protein.

\section{Complementation assays for TPP1 and POT1 coordination}

We next tested whether the TPP1 TEL patch functions in recruitment and activation of telomerase at telomeres could be bypassed by increasing the accessibility of chromosome $3^{\prime}$ ends to telomerase. In previous studies, 
A targeted AAVS1 locus:
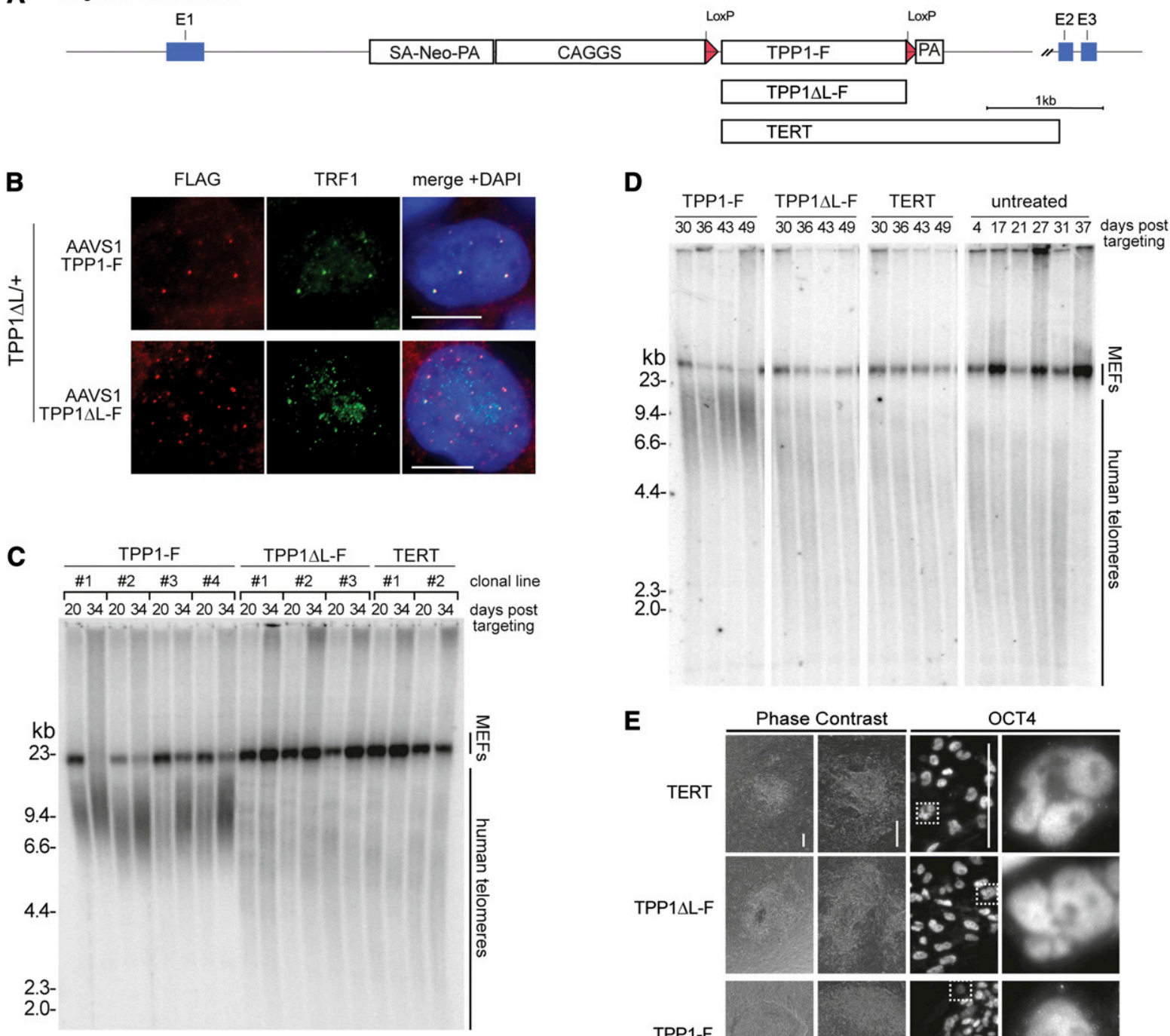

E

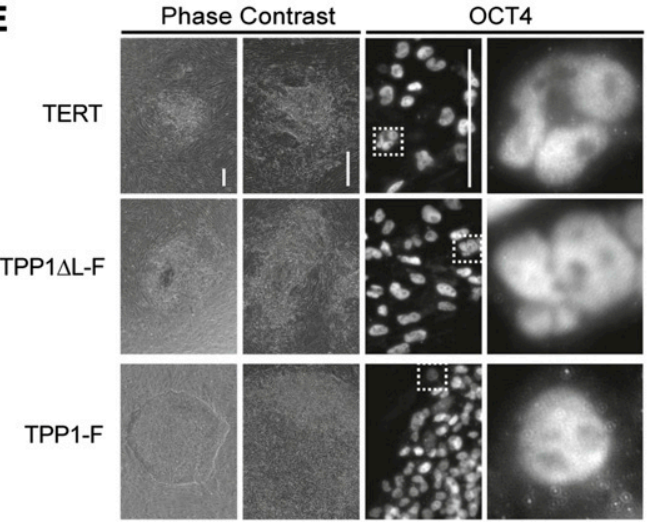

Figure 4. The essential role of the TPP1 TEL patch is not bypassed by telomere or telomerase protein overexpression. $(A)$ Targeting schematic of variants introduced at the AAVS1 locus. (B) IF of TPP1-F and TPP1 $\Delta \mathrm{L}-\mathrm{F}$ in a heterozygous TPP1 $\Delta \mathrm{L}-\mathrm{GFP}$ background stained against Flag and TRF1. $(C)$ Telomere restriction fragment length assay of a TPP1 $\Delta$ L-GFP homozygous line with TERT, TPP1-F, or TPP1 $\triangle \mathrm{L}-\mathrm{F}$ overexpressed from the AAVS1 locus. Samples from individual clonal cell lines are indicated by brackets, each with two time points of continuous passaging. $(D)$ Telomere restriction fragment length assay of cell populations from TPP1 $\Delta \mathrm{L}-\mathrm{GFP}$ cells with TERT, TPP1-F, or TPP1 $\triangle \mathrm{L}-\mathrm{F}$ overexpressed from the AAVS1 locus compared with the AAVS1 untargeted (untreated) parental homozygous TPP1 $\triangle \mathrm{L}$-GFP over a time course of continuous passaging. (E) Phase contrast and IF of late time point hESC colonies targeted at the AAVS1 locus with the indicated constructs and stained against OCT4. Dashed square in the top panels indicates an individual nucleus for each genotype that is shown magnified in the panel at the right. Bar, $200 \mu \mathrm{m}$.

increased chromosome 3' end accessibility influenced telomerase RAP of telomere elongation and also allowed more than one telomerase-mediated elongation event per telomere in each cell cycle (Baumann and Price 2010; Zhao et al. 2011). To investigate whether the TEL patch would remain essential for telomerase action on more accessible chromosome 3 ' ends, we expressed a POT1 variant (POT1 $\Delta \mathrm{OB}$ ) lacking its $\mathrm{N}$-terminal DNA-binding OB (Loayza and de Lange 2003; Lei et al. 2004). We targeted the AAVS1 locus to express F-POT1 $\triangle \mathrm{OB}$, which, as expected, localized to telomeres (Fig. 5C), increased TIF formation (Supplemental Fig. 4 B,C; Takai et al. 2003; Hockemeyer et al. 2007), and led to notable telomere elongation in hESCs with wild-type TPP1 (Supplemental Fig. 4D). On the other hand, F-POT1 $\Delta \mathrm{OB}$ expression in TPP1 $\Delta \mathrm{L} / \Delta \mathrm{L}$ cells did not rescue telomere shortening (Fig. $5 \mathrm{D}$, right panel) and did not delay cell death relative to the TPP1 $\Delta \mathrm{L} / \Delta \mathrm{L}$ genetic background.

When TPP1 and POT1 are added to telomerase elongation assays using a primer with a single POT1-binding site at its 5' end, the TPP1-POT1 heterodimer increases telomerase RAP (Wang et al. 2007). To investigate whether a 
A

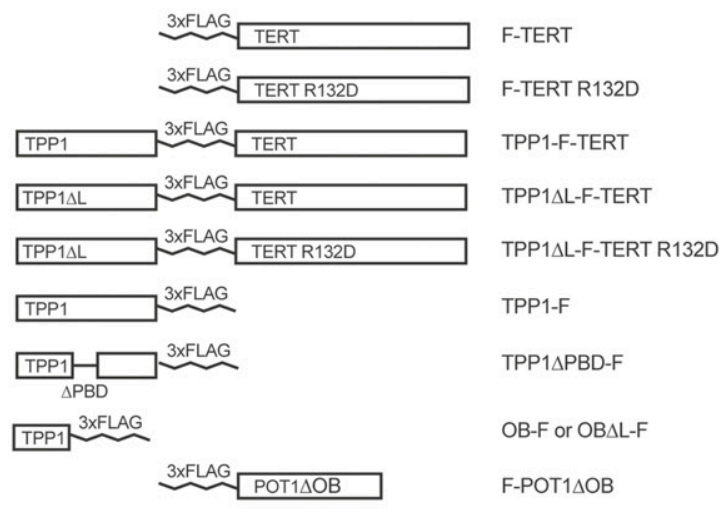

C

TPP1-E-TERT TPP11LL-E-TERT $1 \triangle$ L-F-TERT

F-POT1 $\triangle \mathrm{OB}$

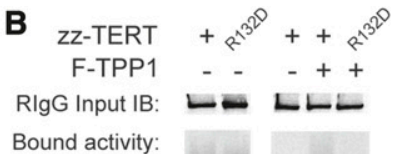

RlgG Input IB:

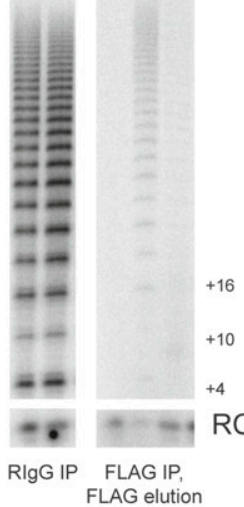

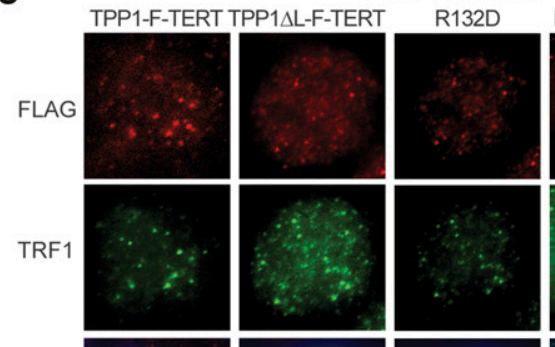
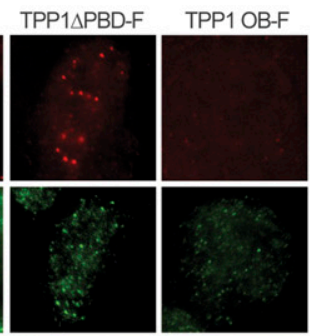

TPP1 OBAL-F
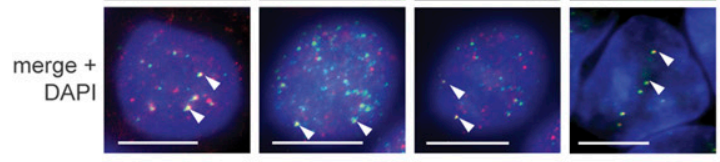

D
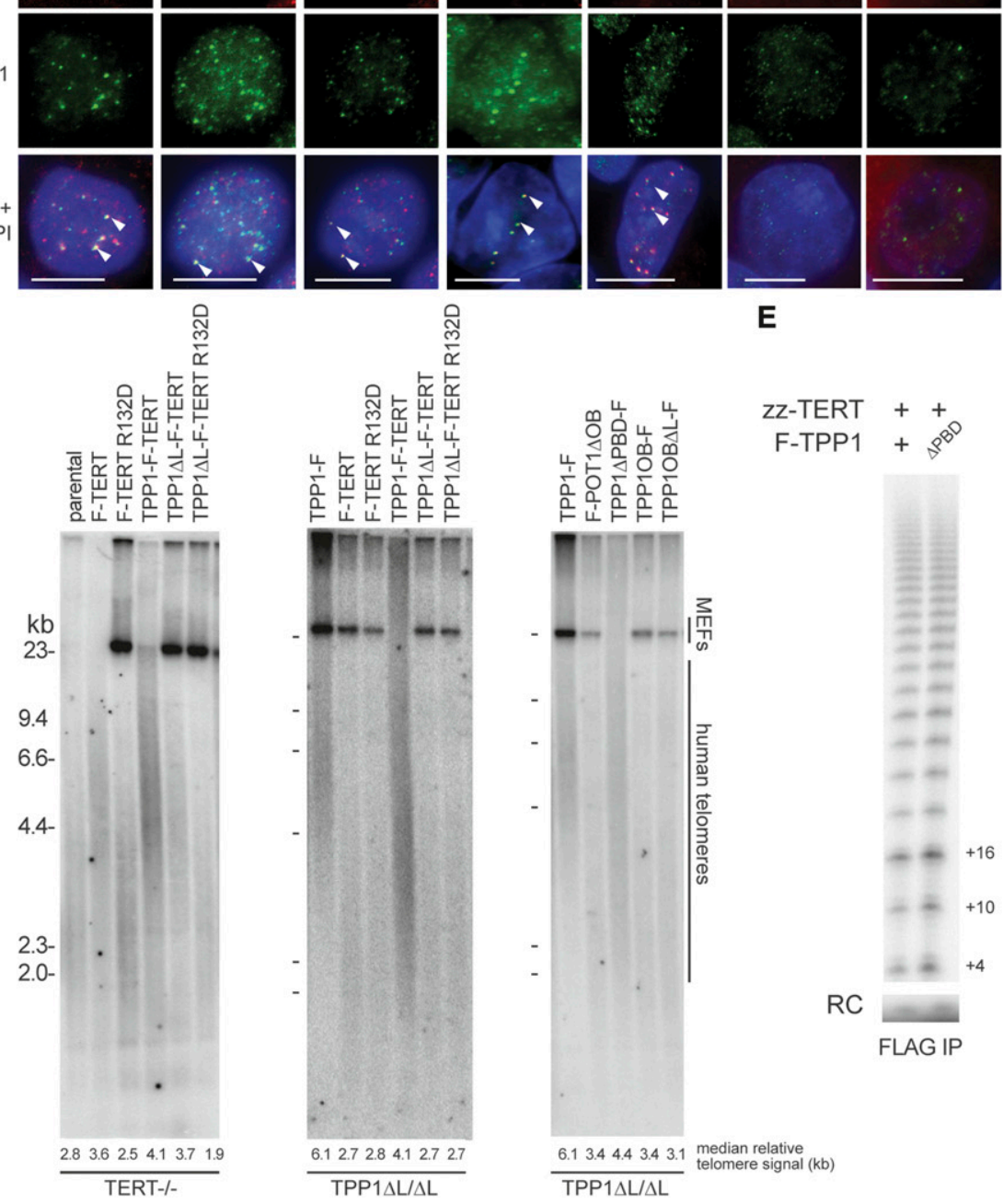

E

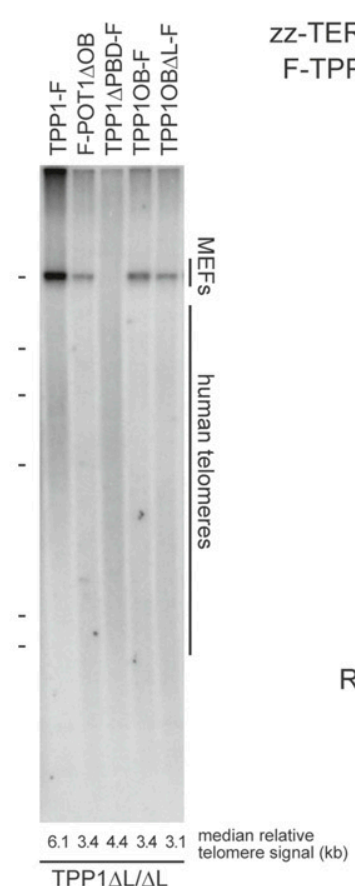

Figure 5. Physical recruitment of TERT to telomeres or increased accessibility of chromosome $3^{\prime}$ ends does not bypass the requirement for TEL patch function in telomerase activation. (A) Schematic of proteins and protein fusions tested for genetic complementation of homozygous TPP1 $\Delta \mathrm{L}$ cells or TERT knockout cells. $(B)$ Telomerase primer extension activity of complexes purified as indicated by zz-TERT or F-TPP1 after overexpression in HEK293T cells. Immunoblot of input zz-TERT is shown in the top panels as a loading control. (RC) Recovery control; (IB) immunoblot; (RIgG) rabbit immunoglobulin G. (C) IF of TPP1-F-TERT fusion proteins, F-POT1 $\triangle \mathrm{OB}$, TPP1 $\Delta$ PBD-F, TPP1 OB-F, and TPP1 OB $\Delta$ L-F. White arrowheads indicate robust protein signal colocalization. Bar, $5 \mu \mathrm{m}$. $(D)$ Telomere restriction fragment lengths in TERT ${ }^{-1-}$ and TPP1 $\Delta \mathrm{L} / \Delta \mathrm{L}$ cells expressing the rescue assay proteins and protein fusions. Note that the same TPP1-F sample is used in the middle and right panels and in Figure 6D. (E) Telomerase primer extension activity of complexes purified by Flag immunoprecipitation after overexpression in HEK293T cells. 
direct 1:1:1 ternary complex of telomerase, TPP1, and POT1 is required for telomerase elongation of telomeres, we targeted the AAVS1 locus of TPP1 $\Delta \mathrm{L} / \Delta \mathrm{L}$ cells to express TPP1 $\triangle$ PBD, a TPP1 variant that lacks the POT1 interaction domain (Palm and de Lange 2008). We verified that TPP1 lacking the PBD had no defect in associating with active telomerase when overexpressed in human tumor cells (Fig. 5E). Consistent with a failure of TPP1 $\triangle$ PBD to recruit POT1 to telomeres, cells expressing TPP1 $\triangle \mathrm{PBD}$ $F$ had an increased number of TIFs relative to wild-type hESCs or cells expressing other forms of TPP1 (Supplemental Fig. 4 C). Despite the increase in TIFs, TPP $1 \Delta \mathrm{L} / \Delta \mathrm{L}$ cells with intragenic complementation by TPP1 $\triangle \mathrm{PBD}$ were rescued for viability in long-term culture. Curiously, telomere length homeostasis in these cells occurred at a set point of abnormally short length (Fig. 5D). This result was unexpected because depletion of POT1 from telomeres generally leads to extensive telomere elongation (Loayza and de Lange 2003; Hockemeyer et al. 2005; Churikov and Price 2008).

The TPP1 OB alone can assemble with telomerase in human tumor cells, detectable by coimmunopurification or IF colocalization, when both telomerase and TPP1 OB are overexpressed (Sexton et al. 2012; Zhong et al. 2012). We therefore tested for rescue of telomere maintenance in TPP $1 \Delta \mathrm{L} / \Delta \mathrm{L}$ cells by expression of the TPP1 OB alone (Fig. 5A). Neither OB-F nor control OB $\Delta$ L$\mathrm{F}$ expression in TPP1 $\Delta \mathrm{L} / \Delta \mathrm{L}$ cells averted cell death or altered the extent of telomere shortening with proliferation (Fig. 5D, right panel). Overall, we conclude that TPP1-mediated recruitment and activation of telomerase does not require a 1:1:1 stoichiometry of telomeraseTPP1-POT1 ternary complex assembly but does require assembly of the TPP1 OB into telomere-localized shelterin complexes.

\section{TPP1 regulates telomerase action by length-dependent telomere feedback}

To further investigate TPP1 OB functions beyond its contributions to telomerase recruitment and activation, we targeted the AAVS1 locus to express additional TPP1-F variants (Fig. 6A). We made mutations within the TPP1 OB TEL patch beyond the acidic residues of the loop that were deleted in the $\Delta \mathrm{L}$ construct by mutating L212, L183, and E215 individually. We also substituted L104, which is on the opposite side of the OB from the TEL patch (Wang et al. 2007). TPP1 L104A substitution has been shown to compromise POT1-dependent RAP stimulation in vitro without reducing TPP1 coimmunopurification of telomerase activity from cell extracts (Nandakumar et al. 2012; Sexton et al. 2012). We also mutated TPP1 S111 to S111A or S111R because phosphorylation of this site was proposed to allow S-phase-specific TPP1-telomerase interaction (Zhang et al. 2013). In addition, because Akt phosphorylation was proposed to modulate telomeraseTPP1 interaction by affecting putative TPP1 homodimerization (Han et al. 2013), we mutated the only consensus Akt phosphorylation site in TPP1 at S498 to generate S498A and S498E. The large panel of substitutions variably reduced TPP1 association with telomerase overexpressed in HEK293T cells, with the largest loss resulting from the L212A TEL patch mutation (Fig. 6B).

We compared the function of TPP1-F proteins with single amino acid substitutions by parallel targeting of AAVS1 in the TPP1 $\Delta \mathrm{L} / \Delta \mathrm{L}$ cells. All of the mutant TPP1 proteins were similarly overexpressed (Supplemental Fig. 4E) and colocalized with telomeres by IF as expected (Fig. 6C). None of them compromised telomerase catalytic activity as assayed in cell extract (Supplemental Fig. 4F). Expression of each of the phosphorylation site TPP1 mutants elongated telomeres and conferred extended proliferation similarly to expression of wild-type TPP1 (Fig. 6D). Expression of TPP1 with a substitution of TEL patch E215 or L183 also led to telomere elongation and rescued cell death, but telomere lengthening was partially compromised compared with that in TPP $1 \Delta \mathrm{L} / \Delta \mathrm{L}$ cells complemented by expression of wild-type TPP1 (Fig. 6D). Cells expressing the TEL patch mutant L212A exhibited telomere shortening intermediate between TPP $1 \Delta \mathrm{L} / \Delta \mathrm{L}$ cells without complementation and cells rescued by wild-type TPP1 complementation and were delayed for, but not rescued from, cell death. TPP $1 \Delta \mathrm{L} / \Delta \mathrm{L}$ cells complemented by expression of TPP1 with an L104 substitution had a distinctive phenotype combining a rescue of long-term culture viability with the presence of very short telomeres, similar in length to those of uncomplemented TPP $\Delta \mathrm{L} / \Delta \mathrm{L}$ cells at the time of culture death (Fig. 6D). Telomeres did not elongate in cells expressing TPP1 L104 variants despite similar levels of telomerase activity coimmunopurification with TPP1 L104A or L104R compared with TPP1 E215A (Fig. 6B), the latter of which clearly supported telomere elongation (Fig. 6D). The short telomere lengths in cells expressing TPP1 $\Delta \mathrm{L}$ and a TPP1 L104 substitution did not induce TIFs (Supplemental Fig. 4C), suggesting that TPP1 disrupted for L104 function mediates telomerase action at critically short telomeres but only at short telomeres, leading to a change in the set point of telomere length homeostasis.

To investigate whether the TPP1 L104 substitutions and other TPP1 variants alter the set point of telomere length homeostasis in a stable manner, we followed telomere lengths over a time course of passaging. Expression of TPP1-F in TPP1 $\Delta \mathrm{L} / \Delta \mathrm{L}$ cells restored telomeres to a length characteristic for wild-type WIBR\#3 hESCs by $\sim 7$ wk of continuous post-selection culture (Fig. 7A,B). The TEL patch mutant TPP1 L183R or E215A supported slower elongation of telomeres, while cells expressing the TEL patch mutant TPP1 L212A died within this interval of culture (Fig. 7A,B). In comparison, the TPP1 L104 substitutions and TPP1 $\triangle \mathrm{PBD}$ did not elongate telomeres yet nonetheless conferred long-term survival $(>120 \mathrm{~d}$ posttargeting) with maintenance of short telomeres (Fig. 7A,B). These findings were independent of the TPP $1 \Delta \mathrm{L} / \Delta \mathrm{L}$ cell line, as an independent clonal TPP $1 \Delta \mathrm{L} / \Delta \mathrm{L}$ cell line complemented by expression of the same set of TPP1 L104 variants had restored viability with similarly altered telomere length set point (Supplemental Fig. 4G). This was also true for TPP $1 \Delta \mathrm{L} / \Delta \mathrm{L}$ cells complemented with expression of TPP1 $\triangle \mathrm{PBD}$ (Supplemental Fig. 4G). Interest- 
Sexton et al.

A

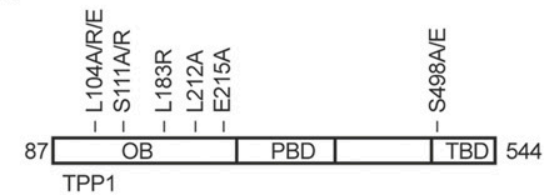

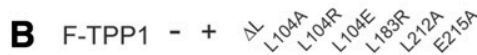

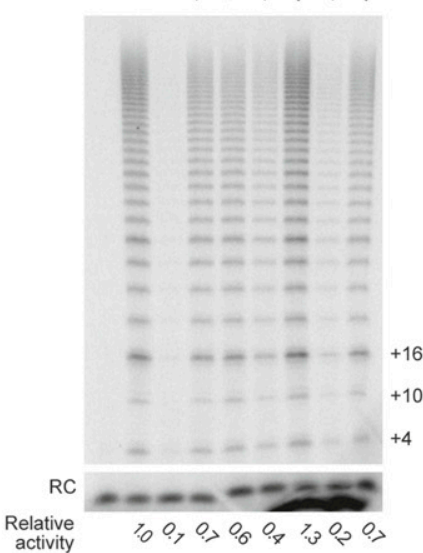

D
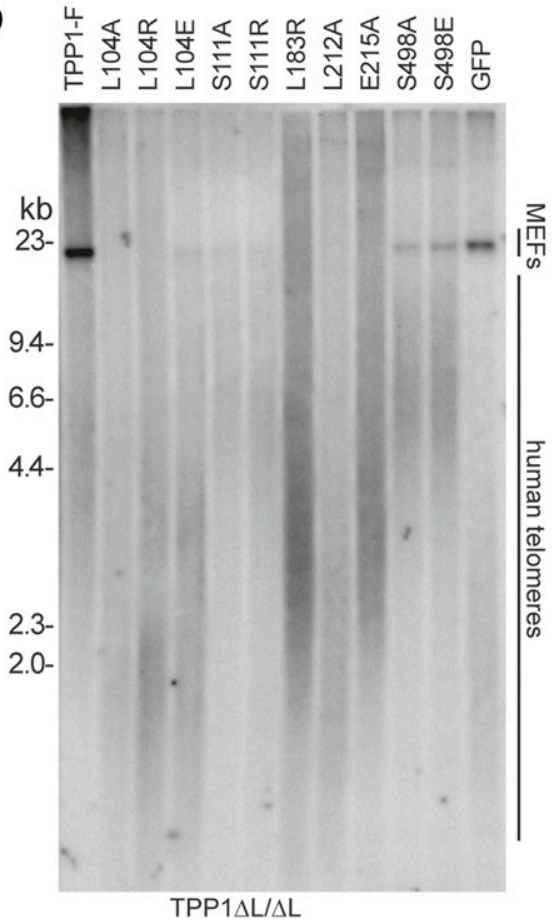

C

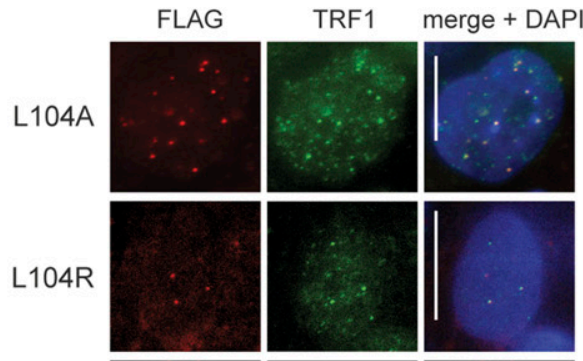

L104E
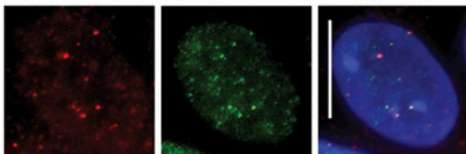

S111A
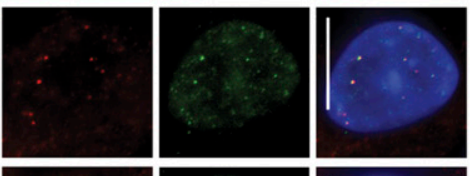

S111R
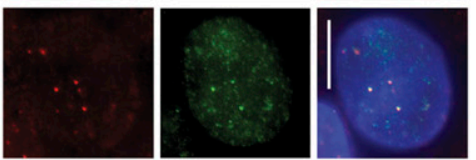

L183R
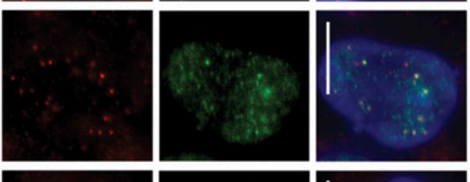

L212A
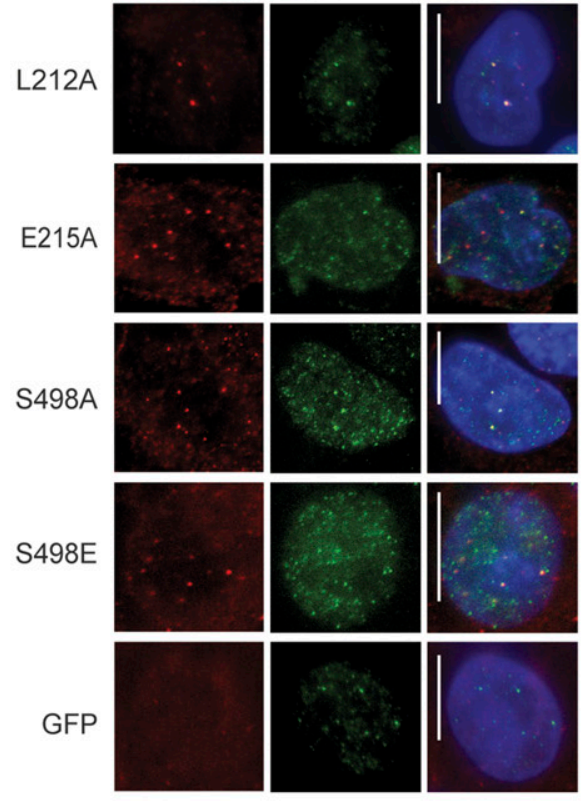

Figure 6. Intragenic complementation resolves multiple TPP1 roles in telomere length maintenance. $(A)$ Schematic of TPP1 variants used for overexpression at the AAVS1 locus. (B) Telomerase primer extension activity of telomerase purified by the indicated TPP1-F after overexpression in HEK293T cells. Relative activity is normalized for background and the recovery control (RC). (C) IF of TPP1-F variants expressed from AAVS1 in the TPP1 $\triangle$ L-GFP background stained against Flag and TRF1, with AAVS1-expressed GFP cells as a negative control for the Flag antibody background. $(D)$ Telomere length of TPP1 $\Delta \mathrm{L} / \Delta \mathrm{L}$ cell lines expressing TPP1 variants. Note that the same TPP1-F sample is used here and in Figure 5D.

ingly, complementation failed to restore telomere length (Supplemental Fig. 4G) or rescue cell death if $\triangle \mathrm{PBD}$ and an L104 mutation were combined in the same TPP1 protein, suggesting that TPP1 L104 and the PBD function in at least partially distinct parallel pathways. We conclude that TPP1 is not only an essential mediator of telomerase recruitment and activation but also a feedback regulator of telomerase action that can influence the homeostasis set point of hESC telomere length maintenance (Fig. 7C). 
A

AAVS1 TPP1-F L104A L104R L104E days post
targeting 2249222835425622283542562228354256

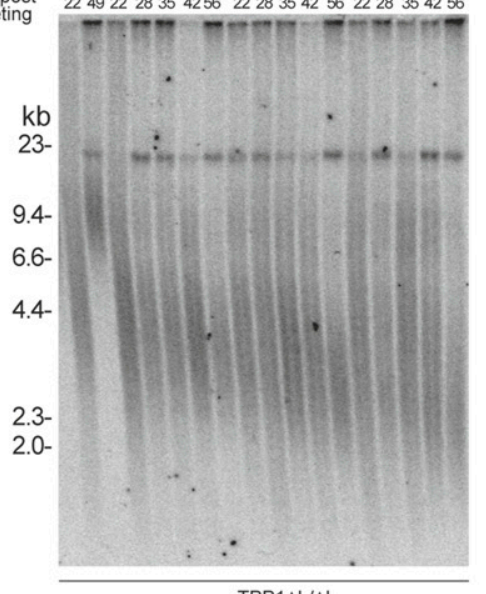

$\operatorname{TPP} 1 \Delta \mathrm{L} / \Delta \mathrm{L}$

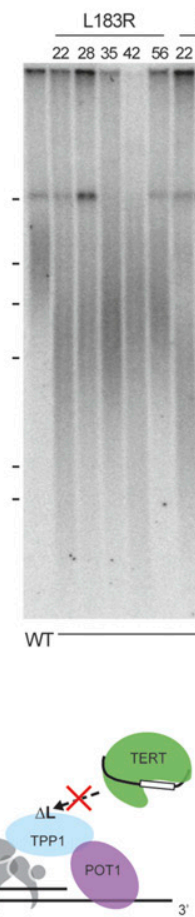

I. Recruitment:

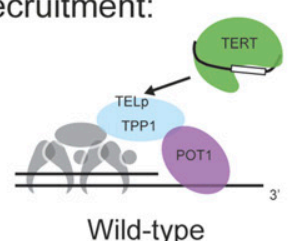

Wild-type
$\operatorname{TPP} 1 \Delta \mathrm{L} / \Delta \mathrm{L}$
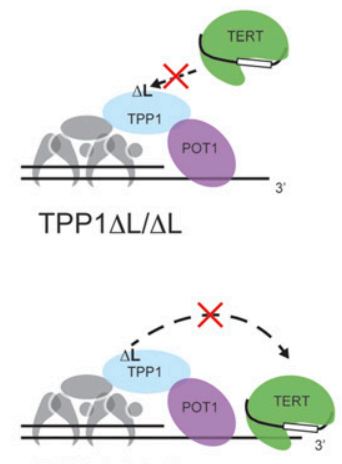

$\operatorname{TPP} 1 \Delta \mathrm{L} / \Delta \mathrm{L}$

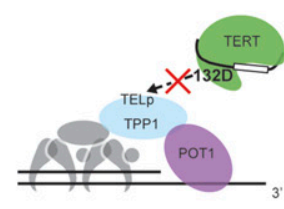

TERT-/-

+TERT R132D
B

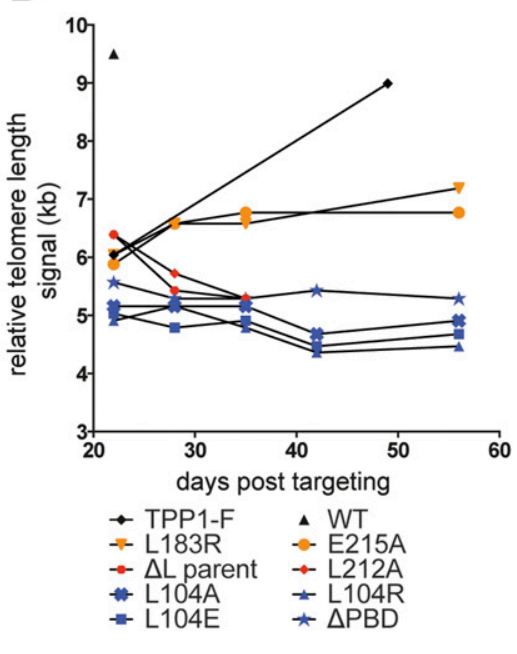

II. Activation:

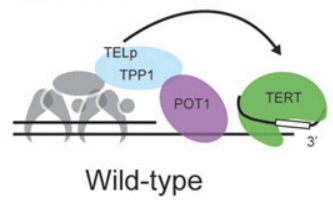

III. Homeostasis Regulation:
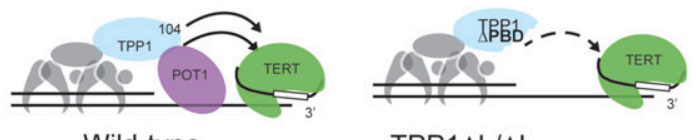

$\mathrm{TPP} 1 \Delta \mathrm{L} / \Delta \mathrm{L}$ + TPP1 $\triangle \mathrm{PBD}$

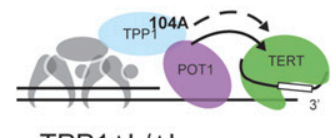

$\mathrm{TPP} 1 \Delta \mathrm{L} / \Delta \mathrm{L}$ +TPP1 L104A

Figure 7. TPP1 separately determines telomerase ability to act on telomeres and the set point of telomere length homeostasis. $(A)$ Telomeric restriction fragment length assay of TPP1 intragenic complementation cell lines over a time course of continuous passaging. $(B)$ Quantification of telomeric repeat hybridization signal lengths. The WT symbol indicates genetically unmodified parental WIBR\#3 hESC telomere length. $(C)$ Schematic of TPP1 functions in determining telomerase action at hESC telomeres resolved in this study. The top schematic (I) depicts the essential function of the TPP1 TEL patch (TELp) in recruiting telomerase. The middle schematic (II) depicts the essential role of the TPP1 TELp in a telomerase activation step. Evidence for this model is derived from the analysis of TPP1 $\Delta \mathrm{L} / \Delta \mathrm{L}$ cells complemented with fusion proteins that bypass the TEL patch requirement for telomerase recruitment to telomeres. The bottom schematic (III) depicts the role of TPP1 in regulating the homeostasis telomere length set point at stable telomere length homeostasis. Evidence for this TPP1 function is derived from the analysis of TPP1 $\Delta \mathrm{L} / \Delta \mathrm{L}$ cells complemented with TPP1 L104A or TPP1 $\Delta$ PBD.

\section{Discussion}

A genetic approach to understanding human telomerase action at telomeres

This study establishes hESCs as a model system for understanding the mechanisms governing telomerase action at telomeres. The tumor cells typically used as model systems to study telomerase function have aberrant telomerase reactivation and relatively short telomeres, whereas
hESCs are constitutively telomerase-positive with a physiological set point for telomere length homeostasis that is characteristic for cells of the early human embryo (Shay and Wright 2005; Aubert 2014). We used state-of-the-art genome-editing technologies to accomplish gene targeting and safe harbor transgenesis in hESCs, thereby creating cell lines with nonrevertible genetic changes of wild-type TPP1 and TERT expression. The ability to completely replace wild-type protein allowed rigorous tests of the biochemical 
interactions that underlie shelterin and telomerase function. In addition to gene knockout and transgene-based rescue, we introduce genetic epistasis and intragenic complementation assays to define the biological functions of TPP1 in the recruitment, activation, and regulation of telomerase action in hESCs.

The TPP1 $\Delta \mathrm{L}$ allele entirely abrogated telomerase function without disrupting shelterin-mediated telomere end protection. The complete loss of telomerase action at telomeres in TPP1 $\triangle \mathrm{L}$ hESCs was inferred from a parallel analysis of TERT knockout hESCs, which phenocopied the telomere shortening and cell death observed for TPP1 $\Delta \mathrm{L}$ cells, and a direct epistasis analysis of double-targeted TPP1 $\Delta \mathrm{L} / \Delta \mathrm{L}$ and $\mathrm{TERT}^{-/-}$cells. These and additional experiments provide a previously missing demonstration of the truly essential role of TPP1 in telomerase recruitment. We conclude that in hESCs, the only mechanism that allows telomere extension is telomerase recruitment via TPP1. In previous overexpression studies, individual TEL patch amino acid substitutions variably reduced TPP1 coimmunopurification of telomerase activity (Nandakumar et al. 2012; Sexton et al. 2012). Paralleling predictions from these studies, different single amino acid substitutions of the TEL patch imposed graded loss of function in hESC telomere synthesis: Complementation of TPP1 $\Delta \mathrm{L}$ by TPP1 L212A delayed telomere shortening and cell death, while cells expressing TEL patch E215A or L183A had telomere elongation intermediate between TPP1 L212A and wildtype TPP1. In contrast to the TEL patch substitutions, phosphorylation-deficient TPP1 alleles showed no difference from wild-type TPP1 function, suggesting that the role of telomere length control by TPP1 phosphorylation in hESCs remains to be elucidated.

\section{Progressive telomere shortening leads to hESC death without induction of telomerase-independent telomere maintenance}

The progressive hESC telomere shortening imposed by TPP1 TEL patch $\Delta \mathrm{L}$ was ultimately lethal, as was the telomere shortening in TERT knockout hESCs. Unlike the case for murine ESCs (Niida et al. 2000), we show here that short telomeres in hESCs did not induce a telomerase-independent alternative mechanism for telomere lengthening. In these cultures, a small population of nondividing differentiated cells remained alive, while pluripotent hESCs underwent apoptosis. This does not necessarily reflect a differentiation-promoting role for critically short telomeres (Batista and Artandi 2013) but could rather represent the accumulation of post-mitotic cells that arises from spontaneous differentiation. Our studies of dozens of cell lines with inhibition of telomerase action at telomeres (Supplemental Table 1), each assayed over months of culture growth, failed to detect any outgrowth of viable cell lines. We therefore conclude that induction of an alternative telomere-lengthening pathway in checkpoint-proficient human stem cells is a very rare event. These findings not only uncover a significant difference between mouse and human stem cell telomere biology but are also relevant to the development of telo- merase inhibition as a therapeutic approach for human cancer. In contrast to most tumor cells, hESCs have genetically intact DNA damage checkpoints, including p53 and $\mathrm{Rb}$ function. Hence, it will be interesting to evaluate in future studies whether telomerase deficiency combined with other genetic manipulations could promote telomerase-independent telomere maintenance in hESCs.

\section{Three functions for TPP1 in telomerase action at telomeres}

Previous studies of cellular phenotypes due to TPP1 depletion demonstrated roles of TPP1 in shelterin-mediated protection of telomere integrity, negative regulation of telomerase through POT1, and telomerase physical and functional recruitment to telomeric chromatin (Palm and de Lange 2008; Lue et al. 2013; Nandakumar and Cech 2013). The resolution of distinct TPP1 roles in shelterin assembly and telomerase action was greatly aided by discovery of the TEL patch dependence of TPP1 association to active telomerase (Nandakumar et al. 2012; Sexton et al. 2012; Zhong et al. 2012). However, in previous studies, the background of wild-type TPP1 expression precluded a determination of whether TPP1 is the exclusive mechanism for telomerase-telomere interaction. In support of the presence of alternate pathways, telomerase action at telomeres had a different biochemical specificity depending on whether it occurred with high or intermediate repeat synthesis processivity (Zhao et al. 2011) and with or without Cajal body association (Stern et al. 2012).

Our data demonstrate that the TPP1 TEL patch provides essential determinants of telomerase action at human stem cell telomeres (Fig. 7C). TPP1 $\Delta \mathrm{L}$ and TERT R132D, each defective for TPP1-telomerase interaction, failed to support telomere maintenance in hESCs (Fig. 7C, schematic I). The TEL patch remained essential for telomere elongation even when chromosome 3' termini were liberated by expression of a truncated POT1, indicating that an increased availability of single-stranded DNA does not bypass the TEL patch requirement. Surprisingly, the TPP1 TEL patch remained essential for telomerase action even if the TEL patch function of telomerase recruitment was bypassed by expression of a TERTTPP1 $\Delta \mathrm{L}$ fusion protein. Likewise, the TERT R132D was not active for telomere elongation even if tethered to telomeres by covalent fusion with TPP1. Thus, the TPP1 TEL patch mediates an essential activation of telomere-bound telomerase (Fig. 7C, schematic II). A similar separation of telomerase recruitment to and activation at telomeres was described more than a decade ago in studies of budding yeast in the demonstration that Est2p (TERT) physical recruitment to telomeres can bypass the genetic requirement for Est1p but not Est3p (Evans and Lundblad 1999). In human cells, telomerase recruitment and activation by the TPP1 TEL patch may be coupled through conformational change of the TERT TEN domain (Nandakumar and Cech 2013).

A third role for TPP1 in telomerase action (Fig. 7C, schematic III) became evident from intragenic complementation assays that physically separated TPP1 roles in 
telomerase interaction from its other roles, including TPP1POT1 interaction. TPP1 missing the PBD could complement TPP1 $\Delta$ L (Fig. 7C, schematic III, middle), indicating that a 1:1:1 stoichiometry of telomerase with TPP1-POT1 is not necessary for telomere elongation. However, telomeres were maintained at very short lengths in cells with complementation of TPP1 $\Delta \mathrm{L}$ and TPP1 $\triangle \mathrm{PBD}$, suggesting that the ternary POT1-TPP1-telomerase complex may stimulate telomerase action. In future studies, it will be exciting to test whether this stimulation is the cellular manifestation of enhanced telomerase RAP observed in vitro upon addition of TPP1-POT1 to enzyme activity assays (Wang et al. 2007). Alternately, the TPP1-POT1 complex could influence telomerase action through a mechanism other than RAP. The establishment of a new telomere length set point in cells expressing both TPP1 $\Delta \mathrm{L}$ and TPP1 $\triangle$ PBD implies a change in the feedback regulation of telomerase action at telomeres but not necessarily a change in the amount of telomeric repeat synthesis per telomere engagement, since the short telomeres of the new homeostasis set point are stably maintained. We speculate that POT1 tethered near telomerase by a bridging TPP1 could promote the initiation of repeat synthesis by orienting the chromosome single-stranded end toward the telomerase active site. This mechanism would differentiate telomerase activation by TPP1-POT1 bound to an extreme chromosome terminus (Fig. 7C) from telomerase-TPP1-POT1 complexes bound internally to duplex telomeric repeats.

The telomerase regulation that requires TPP1 L104 (Fig. 7C, schematic III) can be physically separated from the essential roles of the TPP1 TEL patch. The TPP1 L104 surface is on the opposite face of the OB from the TEL patch (Wang et al. 2007), consistent with a role other than direct TPP1-telomerase interaction. As one possibility, L104 substitution could affect the accessibility of the TPP1 OB to telomerase interaction by changing shelterin protein interaction topology. Since most shelterin components are implicated in telomere length regulation (Palm and de Lange 2008; Stewart et al. 2012), a future key question to address will be how components of the shelterin complex contribute to telomerase regulation individually and/or in coordination. Could shelterin subcomplexes with a distinct composition have a distinct function and form alternate higher-order structures? How do shelterin protein complexes change the action of telomerase action to establish a specific balance of telomere length homeostasis? The genome-editing approach in hESCs described here provides genetic tools to address these questions. It will be particularly fascinating to dissect the genetic distinction between requirements for telomere length maintenance per se and the telomere length set point of homeostasis.

\section{Materials and methods}

\section{hESC culture}

Cell culture was carried out as described previously (Soldner et al. 2009). All hESC lines were maintained on a layer of inactivated mouse embryonic fibroblasts (MEFs) in hESC medium (DMEM/F12 [Invitrogen] supplemented with 15\% fetal bovine serum [Hyclone], 5\% KnockOut serum replacement [Invitrogen],
$1 \mathrm{mM}$ glutamine [Invitrogen], $1 \%$ nonessential amino acids [Invitrogen], $0.1 \mathrm{mM} \beta$-mercaptoethanol [Sigma], penicillin/ streptomycin [Gibco], $4 \mathrm{ng} / \mathrm{mL}$ FGF2 [R\&D Systems]). Cultures were passaged every 5-7 d either manually or enzymatically with $1.5 \mathrm{mg} / \mathrm{mL}$ collagenase type IV (Invitrogen) and gravitational sedimentation by washing three times in wash medium (DMEM/F12 [Invitrogen] supplemented with 5\% fetal bovine serum [Hyclone], penicillin/streptomycin [Gibco]).

\section{ZFN-mediated genome editing}

Gene targeting with ZFNs was performed as previously described (Hockemeyer et al. 2009, 2011). All cell lines created for this study are listed in Supplemental Table 1. TPP1 targeted to the AAVS1 locus was removed with cotransfection of Cre recombinase mRNA and NLS-GFP mRNA (Stemgent) using previously described transfection protocols (Hockemeyer et al. 2009) followed by sorting of GFP-expressing cells and culture of clonally derived hESC colonies with verification of LoxP site recombination by PCR. Targeting of the last exon of the TPP1 genomic locus was excluded due to the presence of the overlapping immediate neighboring gene RLTPR, transcribed in the opposite sense as TPP1.

\section{IF and scoring for nuclear blebbing and TIFs}

For analysis by IF, cells were washed with PBS, incubated with PBS $+0.1 \%$ Triton X-100, washed once with PBS (prepermeablization), fixed with $3.7 \%$ formaldehyde in PBS, permeabilized with PBS $+0.5 \%$ Triton X-100, and blocked with PBS + $0.1 \%$ Triton X-100 with $3 \%$ horse serum. Fixed cells were incubated with antibodies against OCT4 (Abnova), Flag (M2, Sigma), TRF2 (Imgenex), $\gamma$-H2AX (Millipore), TRF1 (gift of Titia de Lange), and GFP (Abnova) in blocking solution followed by secondary antibodies. Cells were imaged on a Zeiss Observer.Z1, and images were processed using Axiovision 4.7.

Scoring of blebbed nuclei was performed single blind. Box plots show scoring of eight individual colonies per cell line at a time point $\sim 2 \mathrm{wk}$ before death of the homozygous TPP1 $\Delta \mathrm{L}$-GFP and TERT ${ }^{-1-}$ lines. $P$-values were derived from a Tukey HSD test performed after significance was determined with an initial ANOVA. Scoring of TIFs was performed single blind; bar graphs show scoring of the indicated lines with $P$-values determined by Fisher's exact test.

\section{ChIP, RNA detection, Southern blotting, and telomerase catalytic activity}

ChIP was performed as previously described (Loayza and de Lange 2003). Protein G-conjugated Dynabeads (Invitrogen) were used to immunoprecipite antibodies. RNA was detected by blot hybridization as previously described (Sexton et al. 2012). Southern blots for detection of genomic insertions were performed as previously described (Hockemeyer et al. 2009, 2011). A PCRbased telomeric repeat amplification protocol (TRAP) assay was performed as previously described using TSNT (AATCCGTCG AGCAGAGTTAAAAGGCCGAGAAGCGAT) as an internal control (Kim et al. 1994). The direct primer extension assay for telomerase activity was performed as previously described (Sexton et al. 2012).

\section{Detection of telomere length}

For preparation of genomic DNA, hESC lines were washed with PBS, removed using $1.5 \mathrm{mg} / \mathrm{mL}$ collagenase type IV from a plate containing a MEF feeder layer, and washed three times in wash 
medium by gravitational sedimentation to minimize contaminating MEF cells. Genomic DNA was then prepared as in the Southern blot protocol. Resuspended genomic DNA was digested with $\mathrm{MboI}$ and AluI overnight at $37^{\circ} \mathrm{C}$. The resulting DNA was normalized and run on $0.75 \%$ agarose (Seakem ME agarose, Lonza), dried under vacuum for $2 \mathrm{~h}$ at $50^{\circ} \mathrm{C}$, denatured in $0.5 \mathrm{M} \mathrm{NaOH}$ and $1.5 \mathrm{M} \mathrm{NaCl}$ for $30 \mathrm{~min}$ with shaking at $25^{\circ} \mathrm{C}$, and neutralized with $1 \mathrm{M}$ Tris ( $\mathrm{pH} 6.0$ ) and $2.5 \mathrm{M} \mathrm{NaCl}$ twice for $15 \mathrm{~min}$ with shaking at $25^{\circ} \mathrm{C}$. Next, the gel was prehybridized in Church's buffer ( $1 \%$ BSA, 1 mM EDTA, $0.5 \mathrm{M} \mathrm{NaPO}_{4}$ at $\mathrm{pH} 7.2$, $7 \%$ SDS) for $1 \mathrm{~h}$ at $50^{\circ} \mathrm{C}$ before adding the telomeric probe ${ }^{32} \mathrm{P}$ end-labeled $\left(\mathrm{T}_{2} \mathrm{AG}_{3}\right)_{3}$. The gel was washed three times for $30 \mathrm{~min}$ in $4 \times$ SSC and once for $30 \mathrm{~min}$ in $4 \times$ SSC $+0.1 \%$ SDS before exposing on a phosphorimager screen.

While this method removed the vast majority of mouse feeder cells, the signal from mouse telomeres was disproportionate to human telomeres due to the amplified relative length and concentration into a smaller area (Kipling and Cooke 1990). Because MEF telomeres were size-resolved from human telomeres, they did not interfere with analysis of hESC telomere length.

\section{Acknowledgments}

We thank Tiffany Tsan and Philip Cleves for technical assistance, and the Collins and Hockemeyer laboratories for helpful comments on the manuscript. G.J.C., P.D.G., C.M.O., and F.D.U. are full-time employees of Sangamo BioSciences, Inc. We thank Titia de Lange for the TRF1 antibody and shelterin cDNAs. R.J. was supported by U.S. National Institutes of Health grants R37CA084198, RO1-CA087869, and RO1-HD045022 and a grant from Howard Hughes Medical Institute. R.J. is an adviser to Stemgent and a cofounder of Fate Therapeutics. K.C. is supported by U.S. National Institutes of Health grant RO1-HL079585. D.H. is a New Scholar in Aging of the Ellison Medical Foundation and supported by the Glenn Foundation as well as the The Shurl and Kay Curci Foundation.

\section{References}

Abreu E, Aritonovska E, Reichenbach P, Cristofari G, Culp B, Terns RM, Lingner J, Terns MP. 2010. TIN2-tethered TPP1 recruits human telomerase to telomeres in vivo. Mol Cell Biol 30: 2971-2982.

Armbruster BN, Linardic CM, Veldman T, Bansal NP, Downie DL, Counter CM. 2004. Rescue of an hTERT mutant defective in telomere elongation by fusion with hPot1. Mol Cell Biol 24: 3552-3561.

Aubert G. 2014. Telomere dynamics and aging. Prog Mol Biol Trans1 Sci 125: 89-111.

Batista LF, Artandi SE. 2013. Understanding telomere diseases through analysis of patient-derived iPS cells. Curr Opin Genet Dev 23: 526-533.

Baumann P, Price C. 2010. Pot1 and telomere maintenance. FEBS Lett 584: 3779-3784.

Bryan TM, Englezou A, Dunham MA, Reddel RR. 1998. Telomere length dynamics in telomerase-positive immortal human cell populations. Exp Cell Res 239: 370-378.

Cesare AJ, Karlseder J. 2012. A three-state model of telomere control over human proliferative boundaries. Curr Opin Cell Biol 24: 731-738.

Churikov D, Price CM. 2008. Pot1 and cell cycle progression cooperate in telomere length regulation. Nat Struct Mol Biol 15: $79-84$.

Evans SK, Lundblad V. 1999. Est1 and Cdc13 as comediators of telomerase access. Science 286: 117-120.
Han X, Liu D, Zhang Y, Li Y, Lu W, Chen J, Songyang Z. 2013. Akt regulates TPP1 homodimerization and telomere protection. Aging Cell 12: 1091-1099.

Hockemeyer D, Jaenisch R. 2010. Gene targeting in human pluripotent cells. Cold Spring Harb Symp Quant Biol 75: 201-209.

Hockemeyer D, Sfeir AJ, Shay JW, Wright WE, de Lange T. 2005. POT1 protects telomeres from a transient DNA damage response and determines how human chromosomes end. EMBO J 24: 2667-2678.

Hockemeyer D, Palm W, Else T, Daniels J-P, Takai KK, Ye JZ-S, Keegan CE, de Lange T, Hammer GD. 2007. Telomere protection by mammalian Pot1 requires interaction with Tpp1. Nat Struct Mol Biol 14: 754-761.

Hockemeyer D, Soldner F, Beard C, Gao Q, Mitalipova M, DeKelver RC, Katibah GE, Amora R, Boydston EA, Zeitler B, et al. 2009. Efficient targeting of expressed and silent genes in human ESCs and iPSCs using zinc-finger nucleases. Nat Biotechnol 27: 851-857.

Hockemeyer D, Wang H, Kiani S, Lai CS, Gao Q, Cassady JP, Cost GJ, Zhang L, Santiago Y, Miller JC, et al. 2011. Genetic engineering of human pluripotent cells using TALE nucleases. Nat Biotechnol 29: 731-734.

Houghtaling BR, Cuttonaro L, Chang W, Smith S. 2004. A dynamic molecular link between the telomere length regulator TRF1 and the chromosome end protector TRF2. Curr Biol 14: 1621-1631.

Kelleher C, Kurth I, Lingner J. 2005. Human protection of telomeres 1 POT1 is a negative regulator of telomerase activity in vitro. Mol Cell Biol 25: 808-818.

Kim NW, Piatyszek MA, Prowse KR, Harley CB, West MD, Ho PLC, Coviello GM, Wright WE, Weinrich SL, Shay JW. 1994. Specific association of human telomerase activity with immortal cells and cancer. Science 266: 2011-2015.

Kipling D, Cooke HJ. 1990. Hypervariable ultra-long telomeres in mice. Nature 347: 400-402.

Lei M, Podell ER, Cech TR. 2004. Structure of human POT1 bound to telomeric single-stranded DNA provides a model for chromosome end-protection. Nat Struct Mol Biol 11: 1223-1229.

Lei M, Zaug AJ, Podell ER, Cech TR. 2005. Switching human telomerase on and off with hPOT1 protein in vitro. I Biol Chem 280: 20449-20456.

Liu D, Safari A, O'Connor MS, Chan DW, Laegeler A, Qin J, Songyang Z. 2004. PTOP interacts with POT1 and regulates its localization to telomeres. Nat Cell Biol 6: 673-680.

Loayza D, de Lange T. 2003. POT1 as a terminal transducer of TRF1 telomere length control. Nature 424: 1013-1018.

Lue NF, Yu EY, Lei M. 2013. A popular engagement at the ends. Nat Struct Mol Biol 20: 10-12.

Nakashima M, Nandakumar J, Sullivan KD, Espinosa JM, Cech TR. 2013. Inhibition of telomerase recruitment and cancer cell death. J Biol Chem 288: 33171-33180.

Nandakumar J, Cech TR. 2013. Finding the end: recruitment of telomerase to telomeres. Nat Rev Mol Cell Biol 14: 69-82.

Nandakumar J, Bell CF, Weidenfeld I, Zaug AJ, Leinwand LA, Cech TR. 2012. The TEL patch of telomere protein TPP1 mediates telomerase recruitment and processivity. Nature 492: 285-289.

Niida H, Shinkai Y, Hande MP, Matsumoto T, Takehara S, Tachibana M, Oshimura M, Lansdorp PM, Furuichi Y. 2000. Telomere maintenance in telomerase-deficient mouse embryonic stem cells: characterization of an amplified telomeric DNA. Mol Cell Biol 20: 4115-4127.

Palm W, de Lange T. 2008. How shelterin protects mammalian telomeres. Annu Rev Genet 42: 301-334. 
Sexton AN, Youmans DT, Collins K. 2012. Specificity requirements for human telomere protein interaction with telomerase holoenzyme. I Biol Chem 287: 34455-34464.

Shay JW, Wright WE. 2005. Senescence and immortalization: role of telomeres and telomerase. Carcinogenesis 26: 867874.

Soldner F, Hockemeyer D, Beard C, Gao Q, Bell GW, Cook EG, Hargus G, Blak A, Cooper O, Mitalipova M, et al. 2009. Parkinson's disease patient-derived induced pluripotent stem cells free of viral reprogramming factors. Cell 136: 964-977.

Stern JL, Zyner KG, Pickett HA, Cohen SB, Bryan TM. 2012. Telomerase recruitment requires both TCAB1 and Cajal bodies independently. Mol Cell Biol 32: 2384-2395.

Stewart JA, Chaiken MF, Wang F, Price CM. 2012. Maintaining the end: roles of telomere proteins in end-protection, telomere replication and length regulation. Mutat Res 730: 12-19.

Takai H, Smogorzewska A, de Lange T. 2003. DNA damage foci at dysfunctional telomeres. Curr Biol 13: 1549-1556.

Takai KK, Hooper SM, Blackwood SL, Gandhi R, de Lange T. 2010. In vivo stoichiometry of shelterin components. I Biol Chem 285: 1457-1467.

Tejera AM, Stagno d'Alcontres M, Thanasoula M, Marion RM, Martinez P, Liao C, Flores JM, Tarsounas M, Blasco MA. 2010. TPP1 is required for TERT recruitment, telomere elongation during nuclear reprogramming, and normal skin development in mice. Dev Cell 18: 775-789.

van Steensel B, de Lange T. 1997. Control of telomere length by the human telomeric protein TRF1. Nature 385: 740-743.

Wang F, Podell ER, Zaug AJ, Yang Y, Baciu P, Cech TR, Lei M. 2007. The POT1-TPP1 telomere complex is a telomerase processivity factor. Nature 445: 506-510.

Xin H, Liu D, Wan M, Safari A, Kim H, Sun W, O'Connor MS, Songyang, Z. 2007. TPP1 is a homologue of ciliate TEBP- $\beta$ and interacts with POT1 to recruit telomerase. Nature 445: 559-562.

Ye JZ-S, Hockemeyer D, Krutchinsky AN, Loayza D, Hooper SM, Chait BT, de Lange T. 2004. POT1-interacting protein PIP1: a telomere length regulator that recruits POT1 to the TIN2/ TRF1 complex. Genes Dev 18: 1649-1654.

Zaug AJ, Podell ER, Cech TR. 2005. Human POT1 disrupts telomeric G-quadruplexes allowing telomerase extension in vitro. Proc Natl Acad Sci 102: 10864-10869.

Zaug AJ, Podell ER, Nandakumar J, Cech TR. 2010. Functional interaction between telomere protein TPP1 and telomerase. Genes Dev 24: 613-622.

Zhang Y, Chen L-Y, Han X, Xie W, Kim H, Yang D, Liu D, Songyang Z. 2013. Phosphorylation of TPP1 regulates cell cycle-dependent telomerase recruitment. Proc Natl Acad Sci 110: 5457-5462.

Zhao Y, Abreu E, Kim J, Stadler G, Eskiocak U, Terns MP, Terns RM, Shay JW, Wright WE. 2011. Processive and distributive extension of human telomeres by telomerase under homeostatic and nonequilibrium conditions. Mol Cell 42: 297-307.

Zhong FL, Batista LFZ, Freund A, Pech MF, Venteicher AS, Artandi SE. 2012. TPP1 OB-fold domain controls telomere maintenance by recruiting telomerase to chromosome ends. Cell 150: 481-494. 


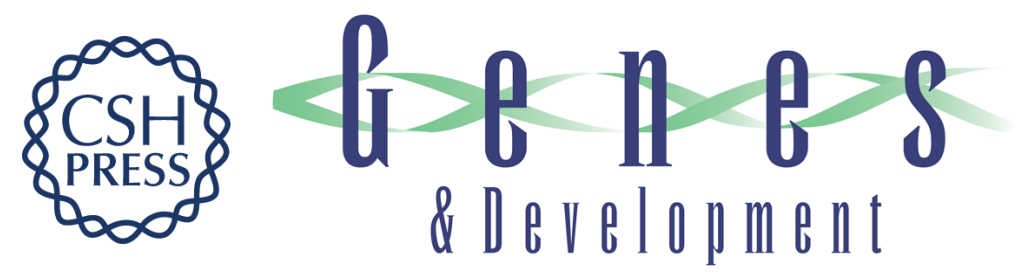

\title{
Genetic and molecular identification of three human TPP1 functions in telomerase action: recruitment, activation, and homeostasis set point regulation
}

\author{
Alec N. Sexton, Samuel G. Regalado, Christine S. Lai, et al.
}

Genes Dev. 2014, 28: originally published online August 15, 2014

Access the most recent version at doi:10.1101/gad.246819.114

\section{Supplemental http://genesdev.cshlp.org/content/suppl/2014/08/08/gad.246819.114.DC1 \\ Material}

Related Content Modern genome editing meets telomeres: the many functions of TPP1

Jan Karlseder

Genes Dev. September , 2014 28: 1857-1858

References This article cites 46 articles, 17 of which can be accessed free at:

http://genesdev.cshlp.org/content/28/17/1885.full.html\#ref-list-1

Articles cited in:

http://genesdev.cshlp.org/content/28/17/1885.full.html\#related-urls

Creative This article is distributed exclusively by Cold Spring Harbor Laboratory Press for the first

Commons six months after the full-issue publication date (see

License http://genesdev.cshlp.org/site/misc/terms.xhtml). After six months, it is available under a Creative Commons License (Attribution-NonCommercial 4.0 International), as described at http://creativecommons.org/licenses/by-nc/4.0/.

Email Alerting Receive free email alerts when new articles cite this article - sign up in the box at the top

Service right corner of the article or click here.

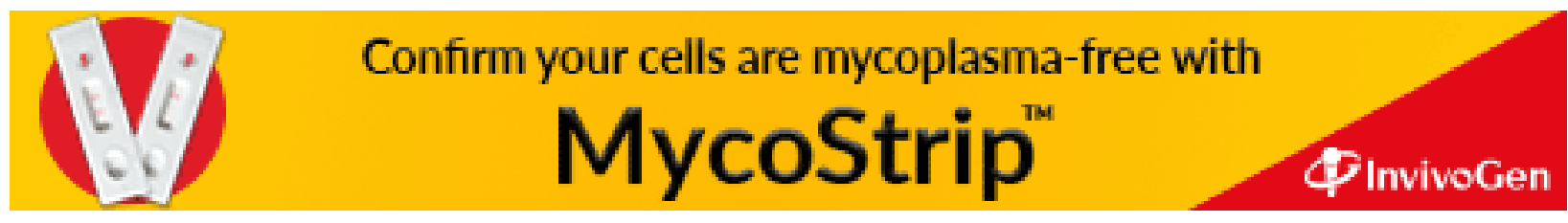

